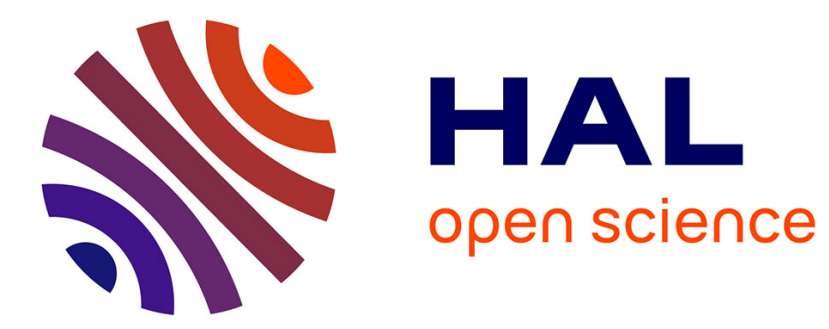

\title{
Dynamic eco-design strategic options for electric-electronic industry
}

Feng Zhang, Maud Rio, Peggy Zwolinski

\section{To cite this version:}

Feng Zhang, Maud Rio, Peggy Zwolinski. Dynamic eco-design strategic options for electric-electronic industry. ED2E 2016 - International Conference on Eco-Design in Electrical Engineering, APIME, Mar 2016, Grenoble, France. hal-01357212

\section{HAL Id: hal-01357212 https://hal.science/hal-01357212}

Submitted on 29 Aug 2016

HAL is a multi-disciplinary open access archive for the deposit and dissemination of scientific research documents, whether they are published or not. The documents may come from teaching and research institutions in France or abroad, or from public or private research centers.
L'archive ouverte pluridisciplinaire HAL, est destinée au dépôt et à la diffusion de documents scientifiques de niveau recherche, publiés ou non, émanant des établissements d'enseignement et de recherche français ou étrangers, des laboratoires publics ou privés. 


\title{
Dynamic eco-design strategic options for electric-electronic industry
}

\author{
ZHANG Feng, RIO Maud, ZWOLINSKI Peggy \\ University Grenoble Alpes, F-38000 Grenoble, France \\ CNRS, G-SCOP Laboratory, 46, avenue Félix Viallet - 38031 Grenoble Cedex 1 - France
}

\begin{abstract}
Today industries from the electric and electronic sector are facing the challenge of improving the environmental performance of the product (eco-design). Various corporate attitudes and their related policy conduct industries to launch different solutions for eco-designing their product and services. Various strategic needs for environmental improvements therefore emerge. In addition important amount of eco-design methods are available. The challenge of planning which eco-design method to be used for a specific need is thus considerably increasing over time. This research therefore aims at providing a mechanism to generate some relevant eco-design options or some sets of methods for answering to the specific corporate orientations chosen.

Existing eco-design methods used in the electric-electronic sector have been carefully analyzed and various 'interactions' between the actions followed in those methods have been identified. From this analysis, this research provides a new network of eco-design actions allowing company to explore different solutions and roadmaps for reaching concrete eco-design requirements.

The company is able to select the solutions that best follow its eco-design needs depending on its specified strategic constraints and their dynamic operational context. Meanwhile, a framework was proposed to guide the company to consider these different eco-design options within its specific context.

This method has been used on a case study, which has demonstrated that its ability to efficiently support the company in reaching eco-design goals.
\end{abstract}

Key words: Eco-design, Electric and Electronic, Environmental management

\section{Introduction}

Today, electrical and electronic industry is facing some serious environmental challenges. With the deepening of the eco-design popularity, especially at a stage of continuing concern with environmental pollution, the ecodesign has been gradually embedded into the macro-development plan of the enterprise. In other words, the ecodesign strategy does not only lead to independent environmental improvements, but also creates important opportunities to support the corporate sustainability covering the ecologic and economic aspects. However the diversity of the corporate requirements raises up the following question: within the different strategic needs for corporate development, especially, the different positioning of environmental responsibilities, does the strategic choice of eco-design need to be defined in different forms? If yes, which forms of eco-design is the best?

This article illustrates the diversity of eco-design strategic choices for given specific corporate needs. This research is based on existing and available theoretical and technical frameworks for conducting eco-design activities from academic and industrial publications and procedures. This diversity allows combining different tactical behaviors, and this may bring a variety of implementation effects. In the first planning phase, a full consideration about this diversity of eco-design strategic options is required to optimize the emergence of an optimal eco-design strategy for different business needs and backgrounds.

In the following sections, this paper firstly clarified 1) if a large number of different eco-design solutions (i.e. embodiments) for a specific environmental problem are already available and 2) if and how the diverse business needs, and the different backgrounds affect the definition of relevant eco-design patterns for those contexts. Based on this investigation (1-2) the authors recommend introducing the diversity of eco-design embodiments options in the early stage of the strategic decision-making. The strategic needs, and especially, their harmonization with other corporate tendency, as well as the integration of past environmental achievements are considered together at the beginning. This paper furthermore demonstrates the integration of diverse eco-design strategic options supports the company to find out an innovative and adaptive roadmap for its business sustainability. 


\section{The vast numbers of eco-design embodiments provides a robust analysis of specific environmental problem considerations}

Within 30 years of development, a vast number of eco-design methods and tools have been developed for answering to multiples environmental demands (Baumann, 2002; Uger, 2008). Still today, more and more environmental aspects are treated by new eco-design methods, supported by software (e.g. LCA for life cycle assessment). These solutions include life cycle analysis methods, covering different life cycle stages, and some methods that is aiming for different purpose, such as "design for X", where X stands for: disassembly, improving the recyclability, material selection, optimizing the use and treatment of natural resources, etc. In 2010 (Ilgin, 2010) has collected more than 500 scientific contributions covering different problems faced only during the recovery process. Facing the vast numbers of methods, a first question would be: "does the link between the environmental aspect and method can be absolute". In other word, "does a concreted environmental topic could be achieved by using different kinds of eco-design methods?" In fact, the answer is yes. For example, to answer the requirements of WEEE directive and to optimize the recyclability of EE product, beside of the classic method of "design for recyclability", lots of others are always available, such as the "design for disassembly", "design for remanufacturing" and "design for material selection". Here, the different methods used could be considered as the different strategic options. In addition, due to the informational interactions between different eco-design methods, some part of a method can be directly used in another one. For instance example is that "design for disassembly" can then embed "design for recyclability" methods to take the recyclability of the parts disassembled. Meanwhile, the typical example is the eco labeling system. Eco-labeling methods propose efficient ways to communicate the environmental performance of a product. But several authors indicated that although the communication is out of the scope of the product strategy, the criteria of eco-labeling can still be directly used as a creditable checklist for guiding the eco-design (Houe, 2009). In this example, the final result of this method is not useful. Only the intermediate information are picked out and valorized.

However, if the research scope is broadened from the pure product design to the whole corporate activities, this kind of interactions becomes ubiquitous. An example can be taken from the duplex links between the product LCA and the classic environmental management system-EMS ISO 14001. The results of the environmental review of EMS might generate a particular specification of product eco-design, because the material inputs and the tooling used in factories have been decided by the design. In this case, eco-design is no longer for a classic improvement of the product performance, but for the optimization of the production process. So, instead of being the classic LCA inventory the results of environmental review of EMS becomes the main input to launch the eco-design process. Inversely, the primary data from manufacturing site and the real environmental improvements furthermore optimize the data quality of eco-design and encourage innovation. Similar examples have been collected. (Zhang, 2012) indicated for instance several interactions between different methods for designing, manufacturing, purchasing, and the communicating. In (Wagner, 2007) seven cases are summarized pointing out that the product environmental innovation can be considered as an additional, nonetheless important, performance metric for organizational environmental management system.

The above discussion indicated that all environmental options (i.e. methods) are not independent. Answering to a strategic need could require the combination of different methods. The relevance of this combination could as well optimize the data quality, and the performance of eco-designing. A systemic analysis of environmental methods was therefore released by (Zhang, 2014). A cartography of environmental actions to deal with the interactions among those methods has been proposed. This cartography includes 46 environmental topics and defines the related action chains (121 actions) for covering these topics. A trace-back mechanism ensures the generation of the multiple eco-design options for treating the problems raised at a starting point (specific need concerning product design and environmental aspects).

The next example demonstrates how to use the environmental actions cartography for constructing multiple potential solutions for a critical problem: the recyclability of electric and electronic products.

Today, facing the stricter requirements from the WEEE directive and the needs from a model of recovery economy, the aspects of "recyclability" of an electric and electronic product became a crucial focus to be optimized. Meanwhile, several other stakeholders, such as the national collect platform, the recyclers and the final users, affect the final performances of the recyclability. A systemic planning within the particular operational contexts should be therefore considered to define the suitable working plan for a "Recyclability Optimization". So, the first step is to find out the most numbers of potential solutions, as more as possible to treat this problem.

Fig. 1: explorative tracing the trajectory for eco-design objective: "Optimization of the recyclability of a product" (extract of (Zhang, 2014)) 


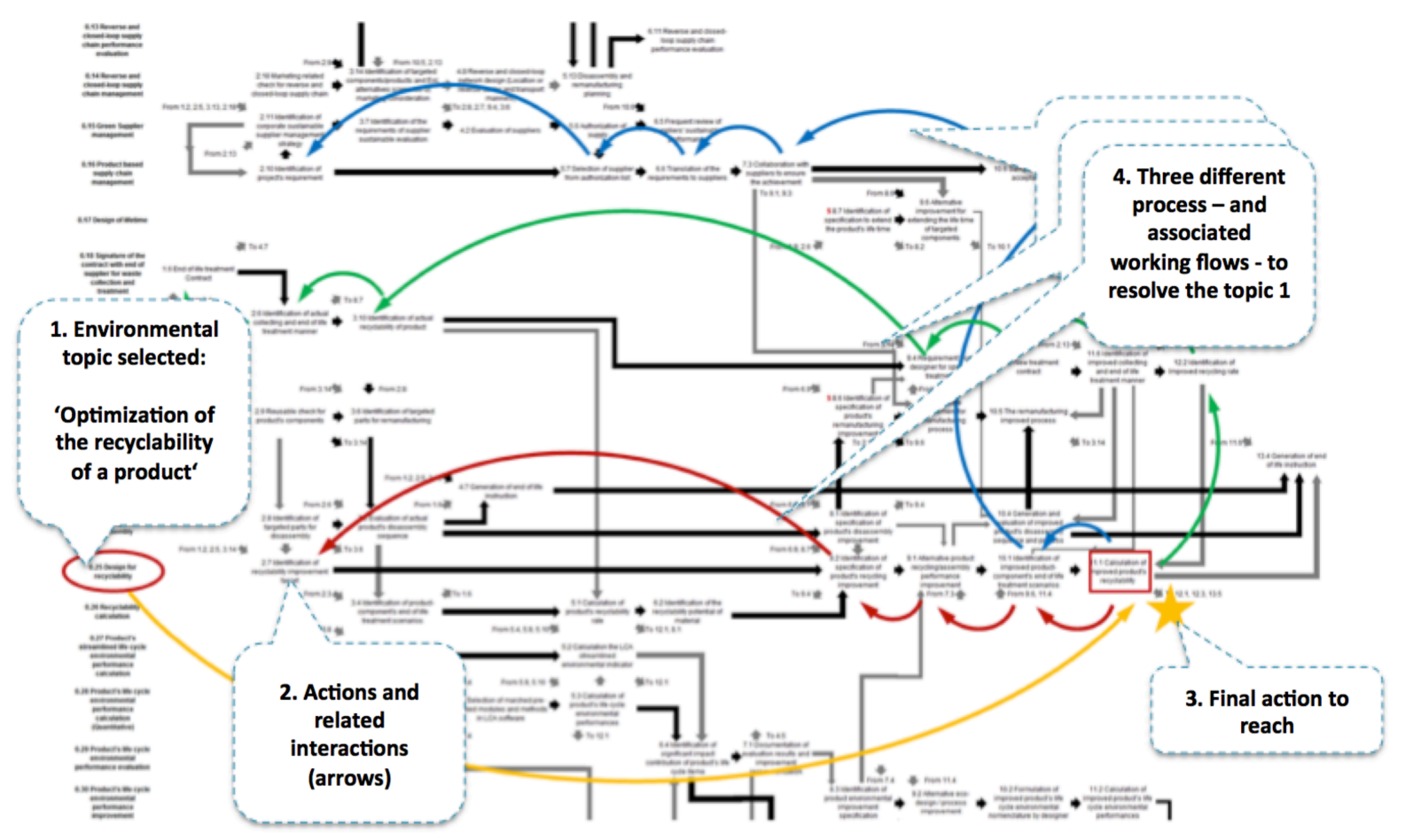

Notes :

1. In the frist left column, the list of 46 different environmental topics, 19 for EMS and 27 for eco-design.

2. The arrows, which string together the actions in a same line, present the process of working flow to resolve the topic.

3. The arrows link across the actions from different lines present the "interactions".

4. The gray arrows represent the parallel possible inputs from other topics and could totally replace the black one.

The above figure (fig.1) presents an example about the different strategic options to answer to an objective of WEEE directive and the recovery economy model: "optimization of the recyclability of a product". The process to explore the solutions will be described as follow:

Facing this objective (rounded in red in the first column of fig.1), the last action in the same line, "Calculation of improved product's recyclability", is the last targeted action to be performed (Fig. 1 - by orange line - the last action in same line with an orange star). This initial objective is achieved once this action has been performed. Then the user of the method needs to identify the previous actions that could drive this final action. If there are multi-parallel previous actions, it means that there are multi-possible ways for resolving this objective (three examples presented by red, blue and green line). All previous actions are registered to describe the different branches (eco-design strategic options). And then, for each branch, by tracing back iteratively the previous actions of these new funds until the initial one which does not have any previous. The footprint of this exploration ensures the construction of a complete trajectory, from the first action to the last one. This constitutes the working process of an eco-design option initial objective.

Fig. 2: trajectories map for eco-design objective: improvement of recyclability of product, from (Zhang, 2014).

Improvement of recyclability of product

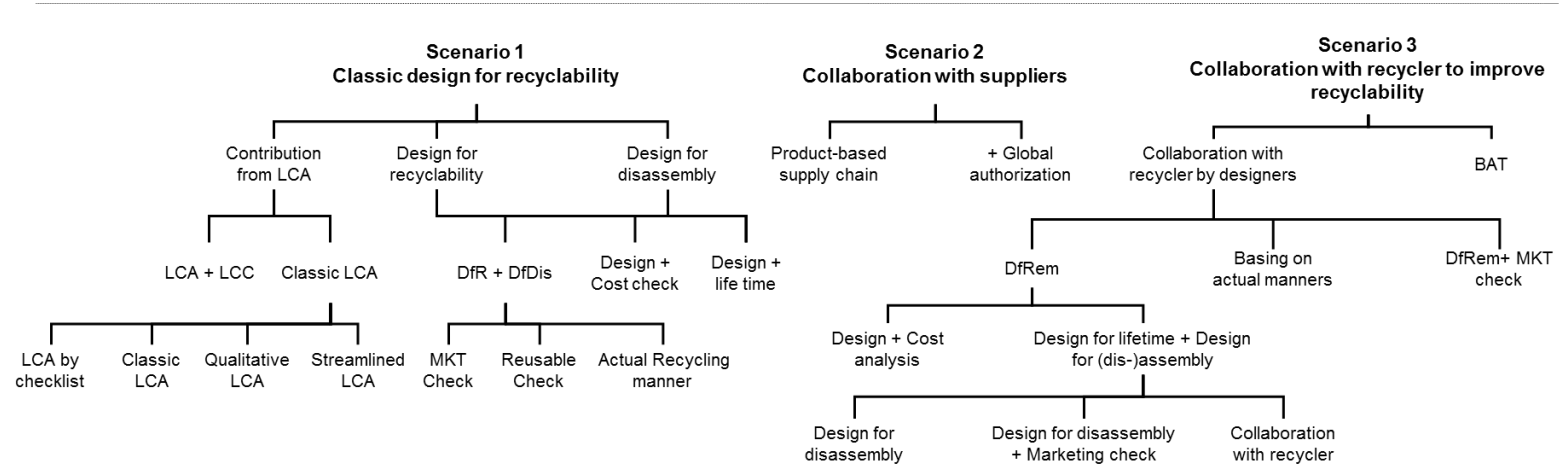

In this example searching the process for "the optimization of the recyclability of a product", 21 different eco- 
design options within three scenarios have been defined (fig.2). The first scenario (the example tracked in red in fig.1) describes the classic option by using the "design for recyclability" method. This option requires the designer to redesign the product depending on some related criteria. The second scenario (the example tracked in blue in fig.1) provides a different strategic option, which requires the suppliers to demonstrate the new feature of recyclability of the product's components. Then the company launches an eco-design project to set up the evaluative criteria, and then, summaries all results to draw up the recyclability of the whole product. In this case, the collaborative activities (such as the evaluation, the annual review, and the cooperation) with suppliers are required to be set up and integrated into the corporate activities. Lastly, the third scenario (tracked in green in fig.1) describes a situation of collaboration between designers and recyclers. In this case, the designer improves the product either by focusing on the real operation of recycling, or by harmonizing and updating the recycling treatment process. An additional action can be taken at a corporate level, even if all real activities are normally out of the corporate scope. The company can sign a specific contract with suppliers to optimize the "taking back" system for its product.

In this model, each branch shows an independent eco-design option (action process). Each of these branches can replace another branch. The redundancy of the branches ensures the robustness for treating this specific problem: "the recyclability improvement of electric and electronic devices" required by the WEEE directive, as well as the new recovery economy models. For example, if the company selects a trajectory (e.g. "collaboration with suppliers" in this example) this redundant design can quickly allow performing a variety of other possible backup options to fulfill the final objective in urgent cases, such as considering the lack of suitable suppliers. So the multiple possible data connection pipes (the interactions among different actions) and multiple contributions of trajectory enhance the robustness about the fault-tolerant ability of the program implementation (Pardo, 2011). It is necessary to mention that the above "applicable scenarios map" provides several possible trajectories, and these trajectories are not strictly independent. It means that the possibility of regrouping the different trajectories provides a great flexibility to plan an adapted corporate program to the company.

Thirdly, these above explored options are not only the general dashboard of the trajectories. In fact, behind each action described through the cartography, sets of operational resources, tools and recommendations are also proposed. These information can support the company to easily evaluate the operability of each trajectory and to integrate the selected trajectory into the corporate process. Such as, due to the WEEE directive, the waste of EE devices were treated by several recyclers. But the detailed data about the collection and the treatment of its product are unavailable for the company. So in order to optimize the recyclability of EE devices, the cartography recommends some scientific researches and case studies (Korean Electronic Association, 2008; EPA, 2001; EPA, Implementations guide for small business recycling cooperatives). This action seeks to guide the collaborations of the designers with these recyclers.

\section{Harmonization of eco-design embodiments with other corporate strategies constructs the sustainability both for ecological and economic aspects}

As mentioned earlier, Eco-design is not a simple matter, especially in the sector of electronics and electric products, where it is part of a system considering quality, cost, security (etc.) as well as sustainability. The multiple stakeholders involved in the supply chain should be considered together to achieve the objective of ecodesigning products and services. From above exploration in figure 1, the different eco-design strategic options require different stakeholders' integrations. The scenario 1 requires the auto-analysis from the product designer. The scenario 2 needs a depth involvement from purchasing departments. The scenario 3 requires some collaboration between designer and recycler. It is therefore necessary to define the responsibilities and the working flow of all stakeholders. However, and seriously, the behaviors of these stakeholders will be constrained by their own professional strategy and related rules, as well as influenced by their own working flows and competences. So new added eco-design requirements cannot be contrary to the original strategy. Otherwise, the execution will be subjected to some great resistance. An example from the purchasing domain can be considered. For a start-up company, if the purchasing strategy is to construct the supplier network within the augmentation of supplier number, a strict supplier control and the remanufacturing options are not a smart option to be taken. The success of remanufacturing would indeed significantly reduce the volume of purchasing. This effect would lead to a risk of creating relationship troubles with the main supplier.

But inversely, if the tendency of eco-design is compatible with other corporate strategies, a suitable eco-design program can cooperate with each other to provide a systemic support of value creation (Hallstedt, 2010, Jorgensen, 2008; De Bakker, 2002; Erlandsson, 2009). Meanwhile, the success of the eco-design depends on the capacities of all stakeholders. It means that even if an eco-design option was successful for a company, it would not absolutely be the case for others. Supplier control is a very simple options about the eco-design programming. But the precondition is that it exist sufficient numbers of suppliers that have the capacity and the motivation to make the co-design by themselves. If we count the cost to train the suppliers and the waste about the ineffective 
communication, this simple option is not feasible.

So, at the beginning of the strategic consideration, serious consideration about the compatibility between the potential strategic options and the global corporate tendency is an important condition for the success of any ecodesign program to design electric and electronic devices.

\section{A decisional framework to optimize the process of eco-design products}

From the section 3, this paper illustrated that the eco-design activities need to be compatible with other corporate strategies. An ideal eco-design strategy can cooperates with other strategies to provide a systemic solution to make the achievement of both economic and environmental aspects together. In order to analyze this compatibility, it is necessary to explore the different potential solutions within the different technical and operational structures. Section 2 demonstrated that based on a depth analysis, a cartography of environmental actions allows the company to finding out the various numbers of solutions for reaching a critical eco-design objective. The different definitions about the technical topics, the responsibilities of stakeholders, and the operational flows provide the data to analyze the compatibility and the possibility of cooperation. The next figure (fig.3) illustrates a framework to support the eco-design program.

Fig. 3: Proposed framework for a systemic eco-design program

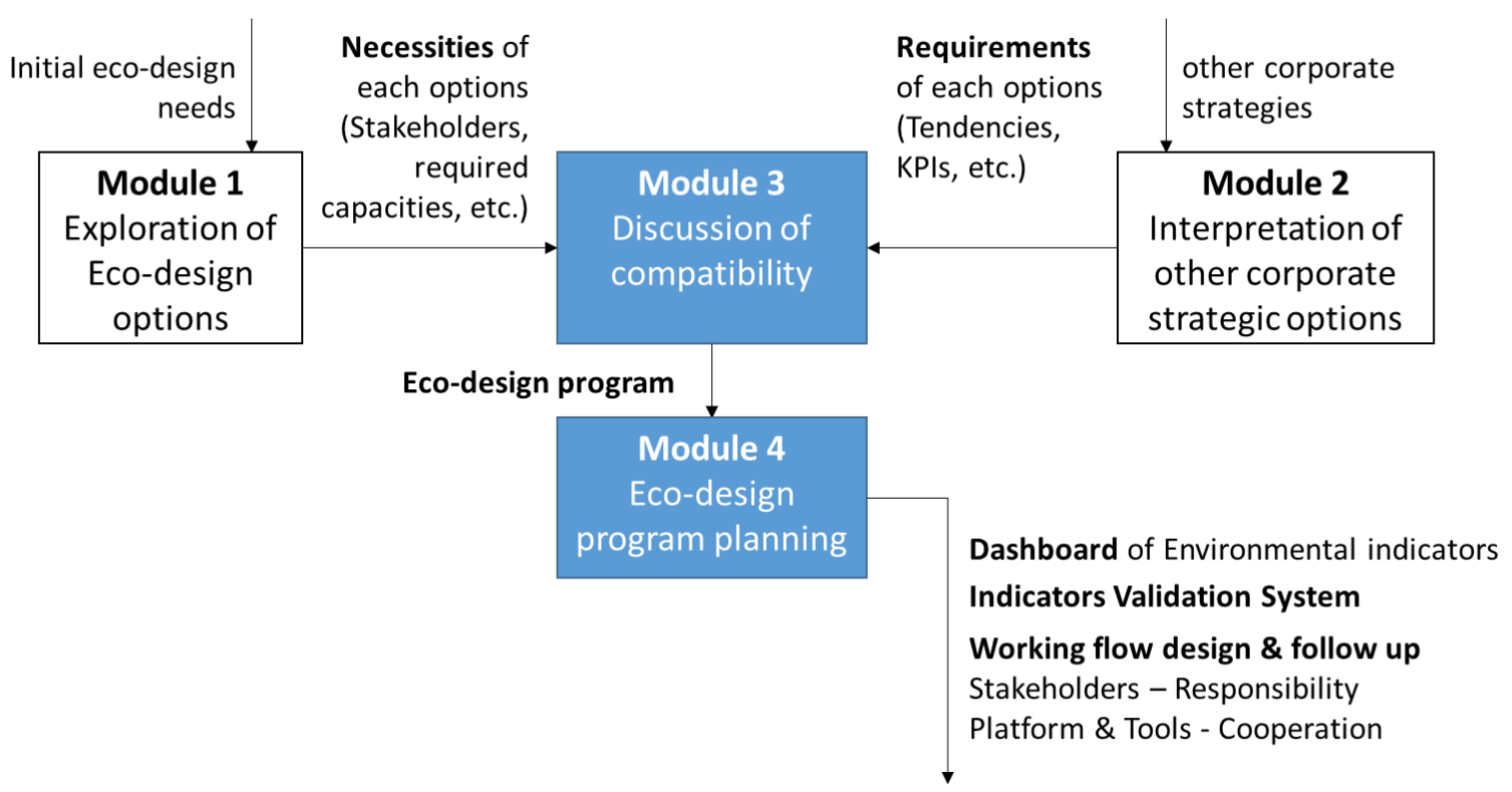

This framework defines a general process to harmonize the new eco-design options with other corporate strategies. This framework includes 4 different modules: the first module explores all possible strategic options of eco-design. The cartography of environmental actions is considered as a database to support this exploration. Within this database, the company could easily translate the eco-design objectives into some different series of eco-design actions and related definitions about required capacities, and responsibilities of stakeholders, as well as the related working flow. The second module is created to translate the principal corporate strategies into sets of key elements or indicators (KPIs). This translation aims to simplify the discussion and allows the comparison with the new eco-design options.

Within these two inputs, the third module focuses on the options compatibilities. In general, the corporate environmental managers might consider some following criteria:

The computability with the corporate strategic definition of environment: today, for the environmental issues, each company has its private definition. According to (Willard, 2005) four different types of strategic definitions about environmental issues have been defined. Some companies consider environment as a barrier for their business development. So there are a few budgets or supports to launch eco-design practices. Facing this definition, the simplest or cheapest eco-design strategic options need to be prioritized. However some other companies consider the environmental issue as a new opportunity for their technical innovation. So they wish to develop some new competences to take some advantage out of it. Facing these needs, the different options should be selected and highlight the ones that would bring some key technologies or which could produce the suitable results.

The compatibility with the KPIs of other strategies: if the new eco-design actions can be aligned to other corporate strategies, the company can significantly reduce the operational cost and the risks associated to those 
actions. For instance the marketing team could be pushing projects dealing with modular ways of selling the products and their services. In this case the "design for upgradability" method could be considered as a better solution for addressing the product end of life instead of "design for recycling" methods. Meanwhile, if the company is re-auditing suppliers, the new requirements about the sustainable supplier could be embedded into this project. And the results of this embedment could directly support the achievement of the related eco-design strategy.

The compatibility with previous environmental plans: due to the relationship between different eco-design options, sometimes, the results of previous eco-design data may be inherited by the next need. This inheritance can directly reduce the operational cost and risks. The eco-label exemplifies this situation: company "A" wants to be certified in type I eco label (ISO 14024) to communicate on the environmental results of its products. However, due to the limited of categories of covered products by the standard this company cannot find out any suitable label system in France (i.e. its products could only covered by a foreign label system). With the support of environmental cartography, the company finds out that some type III eco label (ISO 14025) would fulfill its needs. Meanwhile, some simplified LCA have been released by its designers. Therefore, by proceeding to the type III eco labelling the company just has to modify its Product Category Rule (PRC) in order to answer the needs of labelling system.

The compatibility with parallel eco-design programs: sometimes, there are multiple eco-design programs launched together in company. Some come from corporate level, while others would come from project level. The manager in charge of making the eco-design plan (either on corporate level or project level) therefore needs to consider the compatibilities of these programs. Basically, due to the relationship between the eco-design options, the common actions for multiple objectives can simplify the operational cost and encourage the motivation of stakeholders.

Once the suitable eco-design options have been selected. The last module (number 4) is to create support for the company to define the working process and the responsibilities of each stakeholders. The dashboard with sets of KPIs system, the methods of validation system, and the collaborative platform need to be carefully designed.

This framework and the related cartography of environmental actions had been tested into a French SME to define a suitable eco-design program. This company is an electric and electronic company producing lighting decorations for festivals. The company objective at the beginning was to "optimize the recyclability rate of its product" for being WEEE directive compliant. With the support of the cartography, a holistic scenarios map has been proposed to deal with this consideration. Similar with the above example (shown in fig. 1), there principal scenarios were proposed: 1 - Design for recyclability, 2 - Collaboration with recycler and 3 - collaboration with suppliers. Other branches, such as the "design for disassembly", "design for upgradability" and "design for remanufacturing" have been also proposed to complete the solutions.

Based on these potential solutions, a set of discussions has been organized with the CEO, the purchasing manager, and R\&D managers. The objective of these discussion is to define a suitable eco-design program by considering the compatibilities of these solutions with other current corporate strategies.

Firstly, Due to the lack of necessary internal environmental competences and knowledge, the company preferred the simplest solutions. But due to the lack of available suppliers (most of its suppliers were Asian SME), which had enough knowledge about recyclability improvement, the collaboration with suppliers was not cheap enough. So by initially referring to this preference, the classic "design for recyclability" have been selected and several other solutions, such as the "implementation of the remanufacturing process" were out of scope.

But facing the current corporate strategies, especially the strategy to reduce the volume of purchasing goods from Asian suppliers, and the corporate program to reduce the cost, the planer found out that the "remanufacturing" for its product could directly produce some potential benefits for these two projects. The lighting product and related component had a life stage of 10 years. However these products were only used for 1 year. If these products could be well collected, a major part of the waste could be avoided by remanufacturing the remaining unbroken parts. The recycled product could reduce the volume of purchasing which would indirectly reduce the purchasing cost. So by performing some preliminary benefits calculation, this company decided to make the "remanufacturing" strategy as a long-term tendency of corporate business.

So, within this new context, the actual eco-design initial plan needed to be changed in order to address the new objectives and to consider them as the short-term steps for simplifying the realization of the long-term tendency: remanufacturing. By considering its product profiles (the life time and actual business model allowing the possibilities for tracing and reusing the decorative lighting products and its supports), the "design for disassembly" and "design for lifetime", replaced the "design for recyclability rate". This action plan were therefore selected as the common solution to answer both the short term and long term objective.

The results of this case study demonstrated that the consideration of the compatibilities between the eco-design 
options and other corporate strategies can support the company to find out a more suitable eco-design solution. In this case, firstly, due to the initial preference, the remanufacturing option was out of the scope. But within the consideration of the relationship with other corporate needs, the company redefined a new innovative objective which was never been considered in their mind, and finally remanufacturing has been selected by corporates.

\section{Conclusion}

Today industries from the electric and electronic sector are facing the challenge of improving the environmental performance of the product (eco-design). Various corporate attitudes and their related policies conduct industries to launch different solutions of eco-design. In addition important amount of eco-design methods are available. The challenge of planning which eco-design method to use for a specific need is thus considerably increasing over time. This research therefore aimed at providing a mechanism to generate suitable eco-design options or a set of methods for answering to the specific corporate orientations.

The existing eco-design methods used in the electric-electronic sector have been carefully analyzed and various 'interactions' between the actions followed in those methods have been identified. From this analysis, this research now provides a new network of eco-design actions for company, allowing them to explore different solutions and helping them to elaborate roadmaps for reaching some concrete eco-design requirements.

The results from this research have highlighted that the harmonization with the eco-design options and other corporate strategies is a key element to make decisions. The company is equipped to select the best solutions depending on its specified strategic constraints, as well as the whole dynamic operational context, and of each solutions taken in this context. This research illustrated a framework to guide the company in the consideration of these different eco-design options within its special context. Four compatibilities with other corporate activities have been highlighted. Within this framework and the proposed environmental cartography (Zhang, 2014), a case study in a SME demonstrated that this method therefore efficiently supports the company in reaching eco-design goals.

\section{References}

Baumann, H., Boons, F., Bragd, A., 2002. Mapping the green product development field: engineering, policy and business perspectives. Journal of Cleaner Production, 10 (5), 409-425

De Bakker F.G.A, Fisscher O.A.M, Brack A.J.P., "Organizing product-oriented environmental management from a firm's perspective”, Journal of Cleaner Production, Volume 10, Issue 5, 2002, pages 455-464

EPA, IEMS implementation guideline, United States, 2001, http://www.epa.gov/dfe/pubs/iems/iems_guide/index.htm

EPA, Implementations guide for small business recycling cooperatives http://www.nerc.org/documents/coop/nerc.pdf

Erlandsson J., Tillman A.M., Analysing influencing factors of corporate environmental information collection, management and communication, Journal of Cleaner Production, Volume 17, Issue 9, 2009, pages 800-810

Hallstedt S., Ny H., Robèrt KH, Broman G., "An approach to assessing sustainability integration in strategic decision systems for product development”, Journal of Cleaner Production, Volume 18, Issue 8, May 2010, pp. 703-712

Houe R., Grabot B., "Assessing the compliance of a product with an eco-label: From standards to constraints", International Journal of Production Economics, Volume 121, Issue 1, 2009, Pages 21-38

Ilgin M.A., Gupta S.M., Environmentally conscious manufacturing and product recovery (ECMPRO): A review of the state of the art, Journal of Environmental Management, Volume 91, Issue 3, 2010, Pages 563-591

Jørgensen T.H., “Towards more sustainable management systems: through life cycle management and integration”, Journal of Cleaner Production, Volume 16, Issue 10, 2008, Pages 1071-1080

Korean Electronic Association, Guidance for methodology of calculation of recyclability rate, the proposal for IEC TC111 $H W G$ 4, 2008

Pardo R. J H., Brissaud D., Zwolinski P, “Contribution to the characterisation of eco-design projects”, International journal of sustainable engineering, Volume 4, Issue 4, 2011, page 301-312

Unger, N., Schneider, F., Salhofer, St, 2008. A review of eco-design and environmental assessment tools and their appropriateness for electrical and electronic equipment. Industrial Ecology 5 (1-2), 13-29

Wagner M., "On the relationship between environmental management, environmental innovation and patenting: Evidence from German manufacturing firms", Research Policy, Volume 36, Issue 10, 2007, pages 1587-1602

Willard, B., "The Next Sustainability Wave”, New Society Publishers, Gabriola Island, ISBN/ISSN: 978-7-5004-6142-5, 2005

Zhang F., Zwolinski P, "Toward unified environmental activities in enterprise", Proceedings of the 12th International 
Design Conference DESIGN 2012, pages 1205-1214, Cravat, Croatia, 2012

Zhang F., Zwolinski P, "SimGreen: a serious game to learn how to improve environmental integration into companies", In proceeding of 22nd CIRP conference on Life Cycle Engineering, 2014, Sydney, Australia 